\title{
Three Myths of Intentionality Versus Some Medieval Philosophers
}

\section{Gyula Klima}

\begin{abstract}
This paper argues that three characteristic modern positions concerning intentionality - namely, (1) that intentionality is 'the mark of the mental'; (2) that intentionality concerns a specific type of objects having intentional inexistence; and (3) that intentionality somehow defies logic - are just three 'modern myths' that medieval philosophers, from whom the modern notion supposedly originated, would definitely reject.
\end{abstract}

Keywords: esse intentionale; aboutness; ampliation; appellatio rationis; information; encoding

\section{Introduction: The 'Three Myths'}

After Brentano, intentionality is often characterized as 'the mark of the mental'. In Brentano's view, intentionality 'is characteristic exclusively of mental phenomena. No physical phenomenon manifests anything like it'. ${ }^{1}$ After Meinong, it has also been claimed (although rather controversially) that intentionality, as this characteristic mental phenomenon, concerns a specific type of objects, namely, intentional objects, having intentional inexistence, as opposed to ordinary physical objects, having real existence. ${ }^{2}$ Thus, intentional objects are supposed to constitute a strange ontological realm, the dwelling-place of the objects of dreams and fiction, and other 'weird entities', even inconsistent objects, such as round squares. Finally, it is generally held that intentionality somehow defies logic, as the well-known phenomena of the breakdown of the substitutivity of identicals, the failure of existential generalization, and generally the strange behavior of quantification in intentional contexts (namely, intensional contexts involving psychological verbs, or as the medievals would put it, 'verbs signifying acts of the cognitive soul', and their derivatives) testify. ${ }^{3}$ In this paper, I will refer to these positions as the psychological, ontological, and logical 'myths of intentionality', respectively. The reason is that although these important modern positions are supposed to have come from medieval philosophy,

This article was originally published with errors. This version has been corrected. Please see Erratum (http://dx.doi.org/10.1080/09672559.2013.813197) 
medieval philosophers would be starkly opposed to them. On the basis of the relevant doctrines of some medieval philosophers, especially Aquinas and Buridan, this paper is going to argue that the three positions on intentionality described above are in fact just three modern myths. ${ }^{4}$

\section{The Psychological Myth}

Intentionality is often described as 'aboutness' - the property of being about something. And it is often claimed that no physical entity exhibits this property. It is only mental phenomena that have this curious characteristic; hence we have Brentano's thesis that intentionality, the property of being about something, is 'the mark of the mental' and, as such, it is this property that marks out the subject matter of psychology.

However, despite the fact that Brentano derived his terminology from the scholastic philosophers' discussions of concepts, which they called intentions, and their related discussions of intentional being, or esse intentionale, they would certainly disagree with Brentano's thesis about intentionality, and with good reason. Although medieval philosophers would perhaps agree with the characterization that intentionality is 'aboutness', they would nevertheless deny that this property is exhibited only by mental phenomena. ${ }^{5}$

Thus, for instance, when Aquinas tells us that colors are in the senses in esse intentionale as opposed to esse reale, the real being they have in the wall, ${ }^{6}$ he seems to be in perfect agreement with Brentano's thesis; ${ }^{7}$ but when he says that the same colors also have esse intentionale in the air, the medium between the perceiver and the perceived thing, then we should begin to suspect that by intentionality he means something altogether different from the notion involved in Brentano's thesis. ${ }^{8}$

To cut a long story short, for Aquinas, intentionality or aboutness is the property of any form of information carried by anything about anything. ${ }^{9}$ If we look at his remarks about esse intentionale in this way, all will make good sense. After all, it is not only my perceptions and my thoughts that carry information about my environment, but also the medium carrying this information to my senses and to my understanding. Furthermore, even if I never receive any of this information, the information is there, and qua information it certainly is about the thing that produces it, when the information is encoded by a natural effect of the thing. This is how, for example, the tracks, the scent, or the sounds of an animal, or the light reflected from its body, carry information about the animal - whether these are actually perceived by another (say, its predator) or not. Indeed, in this sense, every effect carries information about its cause, insofar as it is precisely the cause that 'shapes' - i.e., in-forms 
- the effect to be the way it is; whether the effect is similar to its cause in being this way or not; and whether the effect is capable of cognizing its own being this way, or the cause's being the way that allowed it to produce this in-formation or not.

Consider Aristotle's famous example concerning how the impression of a signet ring in a piece of wax encodes information about the shape of the ring itself, which of course he uses to illustrate how our cognitive faculties receive information about their proper objects. The impression in the wax in a way is nothing but that shape - although, of course not numerically the same shape that shapes the matter of the ring itself, but rather the shape shaping the wax taking on the shape of the ring. To be sure, the impression is a negative of the shape of the ring, which nicely illustrates the important theoretical point that the form of the wax where it has taken on the shape of the ring is not only numerically not the same form as the form of the ring, but rather, insofar as it shapes the wax to be in the way the wax actually is, it is not even similar to the shape of the ring in kind; indeed, in a way it is its direct opposite: where the surface of the ring shows an elevation, the shape of the wax shows a depression, and vice versa. However, it is precisely this systematic correspondence resulting from a simple natural process that produces the encoding of information by the shape of the wax about the shape of the ring with such precision that in a reverse process (say, by using pliable clay for the impression, hardening it by fire, and using it as a mold for another golden ring of the same shape), the original shape could even be reproduced in a numerically distinct copy of the original. This is the phenomenon that Aquinas would describe by saying that the shape of the ring exists in the wax in esse intentionale, insofar as the shape now shaping the wax encodes information about the shape of the ring, thus naturally exhibiting the property of aboutness - that is, intentionality. Therefore, this general hylomorphist framework, distinguishing the esse reale and esse intentionale of the same form, naturally attributes aboutness to all forms in esse intentionale, insofar as all forms in esse reale are encodings of the forms that produce them, and thus they are nothing but those forms in esse intentionale (in fact, this is how all created forms in their esse reale carry information about their creator in esse intentionale). But then, it is within this general hylomorphist framework that Aquinas would interpret the more specific forms of cognitive intentionality - that is, the reception of information in cognitive subjects.

Therefore, what fundamentally distinguishes cognitive intentionality for Aquinas from non-cognitive physical phenomena is not that physical phenomena lack intentionality, but rather that cognitive intentionality is exhibited by cognitive subjects, which besides merely receiving information are capable of actively processing and utilizing it in their vital 
operations. ${ }^{10}$ Thus, in more advanced animals, the mere passive receptivity of the external senses is aided by the integrating activity of the common sense, allowing the animal not merely to sense, but also to perceive sensible objects, as persisting through change. Perception is further assisted by sensory memory, allowing besides mere cognition the re-cognition of objects perceived in the past. Furthermore, imagination can further process information recorded in memory, enabling the animal to model its environment in various ways it could be, thereby providing the animal with some sort of foresight. This foresight, assisted by the so-called vis aestimativa that instinctively evaluates the situation for benefit or harm, enables the animal to seek out what is beneficial and to avoid harm. However, this is about all one can say about animal 'intelligence', the word being used in a rather loose sense in contemporary discussions of the issue. For even the 'smartest' tool-making, symbol-using, banana-catching chimp will not do abstract geometry, set theory with transfinite cardinals or theoretical physics or chemistry, or just drive a car following traffic rules, balance a checkbook, pray in a church, invest in stocks, etc. This is because for those truly intelligent activities genuine human intelligence is needed, nourished in a human society with a history that amassed the skills, ideas, etc. of generations and handed them down in language, culture and mores. What makes all this possible is the fact that on top of the above-mentioned cognitive animal faculties, in rational animals, that is, in humans, a further faculty, the intellect or understanding, further processes the sensory information amassed in experience in the form of singular representations of singulars, the so-called phantasms, from which it abstracts the intelligible species, the first universal representations of singulars of various natural kinds. The intelligible species, stored in intellectual memory, then enable the intellect to form universal concepts entering into judgments, the building-blocks of both inductive and deductive reasoning, completing our cognitive mental operations. For 'mental phenomena' for medieval philosophers are, strictly speaking, only the proper operations of a mind (mens) - that is, a rational soul having the cognitive faculty of intellect and the practical faculty of will.

At any rate, this would be a brief sketch of the main cognitive operations of cognitive subjects in the medieval Aristotelian tradition, particularly in Aquinas' rendering (medieval authors had interestingly diverse views and endless debates on the actual psychological mechanisms of these cognitive operations, and accordingly on the distinctions of various stages of the cognitive process). What is important in this sketch, from our point of view, is that all the cognitive operations described here are nothing but different ways of receiving, recording, storing, and further processing information about physical reality. But this aboutness in principle does not differ from the aboutness of the information carried by 
non-cognitive subjects: the difference merely is how the subject uses, or fails to use, this information for the benefit of its own existence.

To make this point more effectively, I think it will be instructive to consider here the view of the nominalist John Buridan, who very often respectfully disagrees with Aquinas in his interpretation of Aristotle's psychology, especially when Aquinas' 'moderate realist' interpretation goes against his own nominalist semantics, metaphysics, and epistemology. But despite all disagreements Buridan has on this score with Aquinas, he definitely agrees with him on the issue of the intentional reception of forms both in cognitive and non-cognitive subjects. Since Buridan's analysis is less known, and it is very clear, while it differs from Aquinas in interesting, subtle details, I think it is justified to quote at length some relevant passages from Buridan's Questions on Aristotle's De Anima (QDA). ${ }^{11}$

Buridan's most detailed account of the issue can be found in his discussion of the traditional question whether sense is an active or a passive power (QDA II, p. 9). After presenting a series of traditional arguments that it is active, he starts arguing for the opposing view as follows:

It will be useful to say some things about the terms that we shall use in this and the subsequent questions. We should note, therefore, that 'sensible' means the same as 'capable of being sensed', and 'sensitive' the same as 'capable of sensing'. And then the first question arises: whether the species of color in air or in the eye ought to be called sensible. And I believe that it ought not, in accordance with the proper meaning of the phrase, for I do not think that it can be sensed. However, by analogy we call it sensible, because it is through it that the thing of which it is the species is sensed, just as urine is called healthy not according to the proper signification of 'healthy', but because it indicates the animal to be healthy.

Having made thus quite clear that the sensory information carried by the medium about the sensible object to the senses (the so-called sensible species) itself is not sensible, a little later Buridan adds that just because the air, for instance, is receptive of and carries such sensible information, on that account it need not be sensitive - that is, a cognitive subject:

The fourth question is what is properly signified by 'to sense'. And it appears to me that 'to sense' does not adequately signify the same as 'to have in itself the species of the sensible thing', for in that case air would sense, namely, it would see and smell and hear. 
Obviously, one hardly needs a clearer denial of Brentano's thesis of aboutness being 'a mark of the mental'. But then, it should also be clear that in the views of both Buridan and Aquinas, who otherwise differ on so many issues, receiving and storing information about physical reality is not the privilege of cognitive subjects; and so if cognitive subjects just further process this kind of information, then the intentionality of all information is not the privilege of cognitive subjects, or generally of their cognitive, or specifically of their mental, psychological states. But this is all we need for dispelling the first myth, as far as the consensus of medieval philosophers is concerned.

\section{The Ontological Myth}

However, all this may not be enough to do away with the second myth namely, the ontological myth about intentional objects. For even if perhaps there is nothing mysterious about the impression of the ring in the wax carrying information about the ring or sense perceptions carrying information about sensible objects, there apparently is something mysterious about objects of imagination and thought: after all, these objects, such as centaurs, golden mountains or even round squares are not objects existing in physical reality, but they are undeniably the objects of our imagination and thought; so what are they, where, or how do they exist? Aren't at least these objects the inhabitants of a distinct ontological realm?

What makes these questions appear plausible is that we can talk about non-existent objects of thought and imagination in pretty much the same way as we do about ordinary objects in our sensible environment. So, we refer to these objects and quantify over them just as we do when we talk about ordinary objects. But then, it seems that by the very acts of reference and quantification we have an 'ontological commitment' to these objects. After all, according to Quine's famous dictum, 'to be is to be the value of a bound variable'. But these objects of our reference and quantification are non-existent, so apparently they have to be there somehow, without actually existing. Or so a 'Meinongian' an argument might go.

There are usually two types of reaction to this line of reasoning. One is the Meinongian reductivist type, giving a reduced ontological status to intentional objects, in a different mode of being. The other is the Quinean-Russellian eliminativist type, trying to explain away what is taken to be merely apparent reference to or quantification over non-existent objects in terms of plausible paraphrases involving only reference to or quantification over ordinary objects. As I have argued at length elsewhere, Buridan, offered an ingenious third alternative 'between' 
these reductivist and eliminativist strategies of handling reference to non-existents. ${ }^{12}$

Without going into the intricacies of Buridan's theory of reference in intensional contexts, or his theory of ampliation of supposition, one must note in the first place that on his view reference (suppositio) is still context-dependent, when meaning (significatio) is already fixed (perhaps even taking into account context and other pragmatic factors as well). In other words, in different contexts, the same term with the same meaning - that is, without equivocation - can be used to stand for different things. For instance, if I say 'Man is a mammal', I intend to refer by the subject term to human beings, however, if I say "'Man" is a noun', the subject of this sentence is meant to stand for a linguistic item that, according to the meaning it has in my first sentence, is a noun. Furthermore, suppose I say in my graduate class, 'All students in this room are graduate students'. In this case, I want to use the subject term of this sentence to refer to the students presently sitting in the room. However, if I say in the same class, 'Just an hour ago, some students in this room were undergraduates', then I am referring either to the students who presently are in the room, or to the students who were there an hour ago, in my undergraduate class. Thus, the reference of the subject of this sentence 'students in this room' is extended, ampliated, to include not only those students who are presently in the class, but also those who were there an hour ago in the past. Indeed, this ampliated subject would refer to the students who were there in the past, even if in the meantime (God forbid!) they ceased to exist.

This is precisely how we can make reference to objects that existed in the past, but no longer do, as in the sentence 'Millions of years ago, dinosaurs roamed the earth'. But the students in my undergraduate class or the dinosaurs this sentence is about are certainly not mysterious, 'intentional objects'. Thus, in these sentences I quantify over non-existent, but entirely non-mysterious, past physical objects. To be sure, they are no longer physical objects; however, they were. But then, one might ask what are they now? Well, the simple answer is: nothing. It is only an existing thing that is something, whatever does not exist is nothing, since no thing is something non-existent. We are just able to make reference to these past objects, because we have information somehow recorded and further processed about them that enables us to identify them and talk about them. And since we can think about such objects in an abstract manner, abstracting from any time, we can talk not only about past things of this kind, but also about future or merely possible things of the same kind as well. As Buridan wrote:

We should note that we can think of things without any difference of time and think of past or future things as well as present ones. 
And for this reason we can also impose words to signify without any difference of time. For this is the way names signify. Therefore, by the specific concept of 'man' I conceive indifferently all men, present, past and future. And by the name 'man' all [men] are signified indifferently, present, past and future [ones alike]. So we truly say that every man who was was an animal, and every man who will be will be an animal. And for this reason it follows that the [verbs] 'think/understand' [intelligere], 'know', 'mean/signify' [significare] and the like, and the participles deriving from them, ampliate the terms with which they are construed to refer indifferently to present, past and future and possible [things] which perhaps neither are, nor will be, nor ever were. Therefore, even if no rose exists, I think of a rose, not one that is, but one which was, or will be, or can be. And then, when it is said: the name 'rose' signifies something, I concede this. And when you say: that [thing] is not, I concede that; but it was. If, then, you conclude: therefore, something is nothing, I deny the consequence, for in the major premise the term 'something' was ampliated to past and future [things], and in the conclusion it is restricted to present ones. ${ }^{13}$

But what about imaginary objects? They are not recalled from the past; neither will they ever exist in the future; nor are they things we experience; nor, indeed, do we think of them in an abstract manner, for we imagine them to be somewhere, somehow, in their singularity. They just appear to be sui generis. So, what are they?

Again, since such things do not exist, they are nothing; so it is just as futile to inquire into the nature of centaurs, etc. as it is to try to draw a round square. Therefore, when we are thinking of things that do not exist, we are not exploring a mysterious realm of non-beings - say, the realm of merely possible or fictitious beings - for, pace David Lewis, there is just no such a realm to be explored. A merely possible being or a fictitious entity is not a special kind of entity; indeed, not any more than a fake diamond is a special kind of diamond or forged money is a special kind of money. Just as a fake diamond is not something that is a diamond and is fake, and forged money is not something that is both money and forged, so a fictitious entity is not something that is both an entity and fictitious. And just as a fake diamond is no diamond at all, and forged money is no money at all, so a fictitious entity is no entity at all.

But then what do we have in mind when we are thinking about objects that do not exist? Well, some of them are things that existed, but no longer exist; others are things that will exist, but do not yet exist; and still others are things that could exist, but actually don't. But what is the 
nature of these things? Well, nothing; just as these things are nothing that is, none of the things there are.

$\mathrm{OK},-$ a Meinongian might want to retort in despair - I give you the word 'thing' (pretty much as Quine did with the word 'being' from 'the other side'). So, these non-existent intentional objects are none of the things we ordinarily encounter in our experience, but they are still not nothing; after all, when I am imagining a centaur or a unicorn, then I am imagining something! So, what is it that I am imagining?

To this, one should answer with a distinction. A 'What is it?' question can be understood in two senses: in one sense, it asks about the nature of a thing known to be real and thus known to have a nature, according to its commonly understood description in terms of its natural or artificial kind. In another sense, this question simply asks about what is meant precisely by the name or description of the (putative) object under consideration. If asked in the first sense, the question of what an imaginary object is, such as what a unicorn is, can only receive the answer that it is nothing, and thus it has no nature. Asked in the second sense, however, the question simply has the force of asking what is meant by the term 'centaur', or of a request for a more detailed description of what is being imagined by one's interlocutor. But then, again, what is merely being imagined is not a being simpliciter; thus, it is not an entity that should, properly speaking, be the concern of anyone doing ontology.

To sum it up, 'the ontological problem of intentional objects' is a problem as long as one takes the domain of quantification to be the same as the extension of an existence-predicate (definable for the logically squeamish as $\left.\operatorname{Ex}={ }_{\mathrm{df}}(\exists \mathrm{y})(\mathrm{x}=\mathrm{y})\right)$ and one takes it seriously that we do quantify over objects that are not any of the objects there are/ exist - that is, are not elements of the domain of quantification. For in that scenario, one can promptly derive the contradiction that there exist some objects that do not exist. So, the 'natural reactions' to the problem may be either the rejection of the homogeneity of the domain of quantification with regard to existence - that is, the Meinongian claim that some objects we quantify over do not exist (but they subsist; or they do not even do that, they are just there as objects of our thought), or the Quine/Russell solution arguing that while the domain of quantification is homogeneous with regard to existence, the apparent cases of quantification over non-existents is just that, merely apparent, as can be shown by the appropriate paraphrases in which the variables bound by our quantifiers range only over the legitimate, existing objects of our universe of discourse. $^{14}$

However, what distinguishes Buridan's and other 'ampliationist' medieval authors' 'solutions' to the problem is that they present not so much a solution to, but rather a dissolution of the problem, by showing it to be 
a pseudo-problem, a philosophical mirage, which upon the correct analysis of quantification in natural languages should not even crop up at all. For in the medieval theory of supposition, we do not have a fixed, uniform domain of quantification for any and all types of propositions, as we do a modern quantification theory. For medieval logicians, the quantifiers, or in their terminology, signa quantitatis, always operate on the range of supposita (context-dependent referents) of the terms with which they are construed. But supposition being an essentially contextdependent semantic feature of our terms, we quantify over as many different domains of objects, in as many different contexts we use our terms to supposit for what we mean by them in those different contexts. Thus, it makes no sense to ask whether the term 'centaur' has supposita without specifying its context (for in 'A centaur is browsing in my backyard' it does not, and in 'I imagined a centaur browsing in my backyard' it does), let alone to ask what sort entities centaurs are, encouraged by the fact that in 'I imagined a centaur browsing in my backyard' I successfully refer to an object of my imagination. To these questions Buridan would merely reply that they are stemming from a failure to understand how intentional verbs such as 'imagine' ampliate the supposition of terms to objects of imagination, of which, therefore we can only say they are imagined, and so they are imagined to be thus and so, but we cannot say what they are and how they are, because they are imagined, but they are not. ${ }^{15}$

In short, Buridan's metaphysical point is that if you want to do metaphysics, then you should deal with being qua being, and not with nonbeing qua being; for then, assuming a contradiction, you might draw just any silly conclusion, after all, ex impossibili quodlibet. So much, then, for the second myth.

\section{The Logical Myth}

But then, if we assume Buridan's stance toward the issue of 'quantifying over non-existents', some puzzles of the third myth are 'automatically' solved. For then, particular quantification in ampliative contexts need not be construed as existential quantification at all. When I say 'Something that does not exist is thought of', this need not be construed as saying that that there exists something that does not exist and is thought of, for of course this would be contradictory. However, if this sentence is construed as saying that some past, future or possible object that does not exist is thought of, then the contradiction vanishes. To be sure, one might still have qualms about 'ontological commitment' by quantifying over mere possibilia; but we just dealt with that issue. Quantification does not involve any ontological commitment. It does involve commitment to objects of our thought, but those objects do not form a special 
metaphysical realm, for, if they do not exist, then they are just nothing (although, without a doubt, they are thought of).

But if we take a closer look at how we are able even to think of such 'nonentities', then, with the help of Buridan's doctrine of appellatio rationis, other puzzles of intentional contexts can also receive plausible, non-mysterious solutions.

When we think of things, we can do so by means of our concepts, encoding highly processed information abstracted from sensory information we gained in experience, and entering into combinations with other concepts in the later stages of our intellectual operations. Thus, when we are thinking of humans or horses, we are using the concepts of humans and horses abstracted from our experiences of these things. And when we are thinking of centaurs, we are combining our concepts of humans and horses to cook up an object of our thought and imagination that is actually nothing, but if it existed would be like a certain combination of a human and a horse. In fact, such combinations take place already in the imagination alone, in a process that is no more mysterious than using your Photoshop (or just the good old brush or pencil) to create images you have never seen before. But the important thing, in any case, is that when we are thinking about any object of our thought, whether real, or made up either by our imagination or by our intellect, our thought always concerns these objects through our concepts; after all, we think of them by means of actually forming their concepts. And this is indeed something characteristic of our mental acts, which is precisely the reason why - in intentional contexts - the terms expressing these concepts obliquely refer to these concepts, or in Buridan's terminology, appellate these concepts. As Buridan put it:

They [the grammatical direct objects of intentional verbs] appellate these concepts in this way because we think of things by means of those concepts, but it is not in this way, i.e., not by means of a concept, that fire heats water, or that a stone hits the ground. ${ }^{16}$

Mental acts, such as thinking, wanting, knowing, believing, doubting, meaning, referring, etc., always concern their objects by means of the concepts (rationes) whereby we conceive of them. This is why in the context of verbs expressing these mental acts, the grammatical objects of these verbs appellate, that is, obliquely refer to these concepts. But then it is no wonder that two terms expressing different concepts, even if they refer to the same thing in the same intentional context, cannot be replaced salva veritate with each other - that is to say, in that context, substitutivity of identicals breaks down. Thus, it is not surprising that Oedipus could want to marry Iocasta, even if he did not want to marry his mother, despite the fact that Iocasta was his mother; for he knew 
Iocasta qua Iocasta, but he did not know her qua his mother. By contrast, he could not have hit Iocasta without hitting his mother, although of course he would not have known that he had hit his mother.

One could go on with illustrations of this sort, showing how the medieval conceptual framework - and in particular, Buridan's logic - provides plausible solutions to all sorts of logical puzzles of intentionality discussed in the contemporary analytic literature. ${ }^{17}$ But, instead of going into such technical details, which are amply discussed in the literature, and which would just divert us from our original, general concern, namely, how the modern notion of intentionality is related to the relevant medieval ideas, it is time to draw some general lessons concerning what we can utilize in our contemporary considerations concerning the phenomena of intentionality from the astonishingly rich and sophisticated medieval philosophical literature on the relevant issues, and how we can do so, given the historical/conceptual gap between the modern and the medieval approach to the same issues.

\section{Medieval Cognitive Psychology as 'Information Science'}

The foregoing sketch of how some medieval philosophers would handle what I called the three 'modern myths of intentionality' was meant to illustrate largely two points. In the first place, many apparently obscure medieval doctrines concerning intentionality will make perfect sense once we interpret them as functionalist theories of receiving and processing information by both cognitive and non-cognitive subjects, mostly disregarding the particular physical mechanisms that realize these operations, pretty much as we theorize about computing functions, disregarding their hardware implementation. In the second place, the foregoing discussion was meant to show that gaining an understanding of the relevant medieval theories in this way has not only a historical, but also a purely theoretical payoff: a better understanding of the phenomena of intentionality itself.

As to the first of these points, I should emphasize in the first place that this is meant to be a general methodological remark, which can be helpful for us to keep in mind both as historians or historically minded theoreticians and as 'pure theorists'. For looking at intentionality as 'aboutness' in the sense of being the property of something carrying information about something considered precisely in this capacity (namely, in its capacity of carrying information about something) allows us to view mental acts, whatever they are in their own nature, precisely in terms of their capacity as information-carriers, regardless of the hardware (or 'wetware', if the hardware is supposed to be the brain, or 'vaporware', if we are allowed to hijack the term from computer lingo, if the hardware is supposed to be some purely spiritual mind) - that is, 
regardless of the nature of the thing that happens to carry this information. Also, in this approach, we can view the objects of these mental acts as the precise content of this information, i.e., whatever this information is about, considered precisely in terms of the information carried about it by the mental act we are considering.

The theoretical advantage of this 'functionalist/information-theoretical approach' to mental acts is that talking about them in terms of their intentional/representational properties alone does not commit us to any particular view about the ontology of concepts (or other mental representations) or their objects. To be sure, this does not have to mean that certain types of intentional features concepts have would not entail anything concerning their ontology. On the contrary, one of Aquinas' arguments for the immateriality of the intellect is based precisely on the alleged ontological implications of the difference between singular and universal mental representations. (The former, phantasms, Aquinas argues, must be material because of their singular mode of representation, whence, by contraposition, the universal, i.e., non-singular intellectual concepts must be immaterial, because of their universal mode of representation.) However, the methodological point I am stressing here is that looking at mental acts precisely as information-carriers assumes the minimum we just directly know about them, by virtue of being able to think with them, without presuming anything we do not directly know about them, such as their intrinsic nature.

Also, looking at concepts in this way dispels not only the mystery of their own nature, but the alleged ontological mystery of their objects as well. If concepts or any other cognitive representations are treated merely as packets of information, then their 'built-in' aboutness will have to concern objects that such representations can possibly carry information about. And of course, such representations can carry information not only about objects that caused these representations, but also about objects that will be caused by these representations, through the activity of the subject having these representations. For cognitive representations are not only receptive of information about their pre-existing objects, but also effective of the formation of their not-yet-existing objects, by being presented by the cognitive faculties of the cognitive subject to its active, appetitive faculties, impelling the cognitive subject to realize their desirable object through its action. Viewed from this angle, the alleged 'mystery' of the non-existent objects of cognitive faculties is not only not a mystery, but a literally vital necessity for any active cognitive subject that without the desire for realizing an as yet unrealized object of its cognition would just not survive (a wolf that never hunts will just die).

Furthermore, this way of looking at medieval theories of intentionality will dispel all confusion concerning 'strange terminology' apparently concerning 'weird entities' introduced on the basis of 'fuzzy criteria of 
identity'. For when medieval philosophers start talking about the form of the object being received not in esse reale, as in ordinary causation, but in esse intentionale vel spirituale, as in the reception of information (especially, but not exclusively) in a cognitive subject, modern readers may easily throw up their hands and roll their eyes over medieval 'mysticism', apparently assuming over and above ordinary physical processes some sort of extra-ordinary, non-physical form of causation. However, if the same modern readers turn to a down-to-earth scholastic philosopher like Aquinas or Buridan, then they can pretty soon get over their misgivings, once they realize that all these authors are talking about is that ordinary causal processes, besides producing their ordinary physical effects according to the ordinary laws of nature, at the same time serve to transfer information about the causes of these processes in a natural system of encoding that information, which is vital information for the cognitive subjects receiving it. Thus, when Buridan explains what one should understand by the esse intentionale of a form of an object in a cognitive subject (a so-called species of the object in question), he makes very clear the following points:

- The species is not something that does not have real being in the subject; on the contrary, it is some real, inherent quality of the receptive subject that does not have this quality on account of its own nature, but can have it upon the causal impact of the object (so, no 'spooky' extra-physical being has to be involved).

- The species, insofar as it is a quality of the subject, does not have to be of the same kind as the feature of the object it represents; on the contrary, if the receptive subject is not assimilated in esse reale to its object by taking on the same kind of quality the object has in esse reale (as in the case of a hot object making a cold subject hot), it may still receive information about the object through a systematic match of its qualities received in esse reale with the features of a different kind of the object (as elevations of the surface of the signet ring are encoded by depressions of the surface of the wax, or bright spots of the surface of the object are encoded by dark spots of photosensitive film, etc.); so, the features of the object thus matched by the real qualities of the subject are nothing but the forms of the object in esse intentionale in the subject, i.e., features of the subject encoding information about the object in a natural system of encoding (which can then also be decoded, producing a copy of the original).

- What is necessary, therefore, for cognitive representation (intentionality) is a systematic match between a range of features of a kind of objects (say, colors in visible objects, or sounds in 
audible objects) and a corresponding range of features of the receptive subject.

- What is sufficient for cognitive representation (intentionality) is that the information carried by the cognitive act is processed by the cognitive subject as vital information - that is to say, that the information in question is received by a cognitive subject that is adapted to react in its vital operations or act in response to the features of the object these representations carry information about.

If we re-read Aristotle's De Anima and its medieval commentators with this interpretation in mind, then all the apparent 'spookiness' and obscurity of the relevant discussions will vanish and we shall find a perfectly sensible and down-to-earth discussion of what we can learn about the nature of the soul through a careful functionalist analysis of its activities, dispositions, habits, and essential powers that enable it to have these activities in the first place.

But then, with regard to the second point mentioned at the beginning of this concluding section, this is also the most important methodological lesson we can learn concerning our own, contemporary investigations into the phenomena of intentionality: if we want to know what they are, we need to inquire into what sorts of things exhibit it, under what circumstances, based on what abilities, stemming from what nature.

Finally, and this is the 'meta-lesson' of the entire foregoing discussion, if we really want to carry out these investigations without any bias or unreflected preconceptions, then we should not do so from the perspective of one pre-established, historically inherited, and thus mostly uncritically presumed conceptual apparatus alone; for that can only lead to 'intellectual provincialism' and 'tunnel vision' of our subject. In order to have a broader view, we should consider at least a couple of other, paradigmatically different articulations of our problems, which in the case of the phenomena of intentionality have to be the views of at least some medieval philosophers, from whom the idea originated.

Fordham University, New York, USA

\section{Notes}

1 Brentano (1995), p. 89.

2 This idea comes in many shades and colors; here I will simply take a 'Meinongian' to be anyone who is willing to distinguish in their domain of quantification entities that belong to a subdomain of it (say, existents or existent entities) and those that are outside this subdomain (say, merely subsistent entities or beings); obviously, from this perspective, terminological variations are of no importance. 


\section{INTERNATIONAL JOURNAL OF PHILOSOPHICAL STUDIES}

3 As we shall see in more detail, from a logical point of view, intentional contexts can be treated as a subset of intensional contexts in general, and with good reason: the more generic feature of intensionality requires the semantic evaluation of our phrases to be dependent on situations other than the actual one; but our ability to do so is dependent on our ability to perform mental acts that can concern such situations in the first place, and it is precisely such mental acts that are signified by the intentional verbs and their cognates in question.

4 This paper derives from a lecture I gave at the 7th Annual Hawaii International Conference on Arts and Humanities, 9 January 2009, in Honolulu. Since that lecture did not address a specialist audience, as neither does this paper, it should come as no surprise that the main theses advanced here namely, that the three modern positions concerning intentionality discussed below would not be endorsed without further ado by medieval philosophers are well known by specialists, who have thoroughly discussed the topic for decades. The point of this presentation is to make the main results of those discussions available to non-specialists (without the otherwise inevitable technicalities of a specialist discussion), and to provide an opportunity for reflection on the paradigmatic differences of the medieval and modern notions, thereby highlighting some of the otherwise unquestioned presumptions of modern discussions.

5 But then, of course, we shall also have to clarify exactly where and on what grounds they would draw the 'demarcation line' between mental and nonmental phenomena, an issue that I'll return to in a moment.

6 Cf. 'sensus recipit formam sine materia, quia alterius modi esse habet forma in sensu, et in re sensibili. Nam in re sensibili habet esse naturale, in sensu autem habet esse intentionale et spirituale.' Sentencia De anima, lib. 2, 1. 24, n. 3. See also the quotes in n. 8 .

7 Granting, for the time being, the modern (post-Cartesian) usage that would classify even sensory operations as 'mental'. Aquinas would reject this usage, because he would regard only intellectual or voluntary operations as properly mental, namely, the proper operations of a soul having intellect and will, properly called a mind, mens, in Latin.

8 'Nam ipse Angelus est forma subsistens in esse naturali, non autem species eius quae est in intellectu alterius Angeli, sed habet ibi esse intelligibile tantum. Sicut etiam et forma coloris in pariete habet esse naturale, in medio autem deferente habet esse intentionale tantum.' Summa Theologiae I, q. 56 a. 2 ad 3; 'medium recipiat alio modo speciem coloris quam sit in corpore colorato ... Actus enim sunt in susceptivis secundum modum ipsorum: et ideo color est quidem in corpore colorato sicut qualitas completa in suo esse naturali; in medio autem incompleta secundum quoddam esse intentionale; alioquin non posset secundum idem medium videri album et nigrum.' Sentencia De sensu, tract. 1, 1. 5, n. 4.

9 Cf. Cohen (1982), Haldane (1983), Hoffman (1990), Tweedale (1992), Pasnau (1997), Perler (2002).

10 Again, this observation has already been made by Sheldon M. Cohen in his paper mentioned in the previous note, and has often been repeated in the specialist literature, say, by Pasnau and Perler in their respective studies referenced there.

11 Buridan's text is as yet unavailable in a critical edition. The relevant passages were first edited by Peter Sobol in his $\mathrm{PhD}$ thesis. Currently, a critical edition of Buridan's entire work is being edited by an international research team of scholars under my direction. To find out more about the project, please visit 
the project's web site, http://buridanica.org. The translations of the quotations from the working draft of the critical edition are mine.

12 Klima (2009), c. 7. In this context I will conveniently disregard Brentano's original idea that even what we would normally take to be real, physical objects, would on his view be just phenomena, ontologically on a par with imaginary objects, but indicating something real, although in itself inaccessible to our consciousness, as presented by Tim Crane (2006), pp. 20-35. After all, as we shall see, the question of 'the problem of intentional objects' will turn on the homogeneity vs. non-homogeneity of the domain of quantification, and from this perspective it is irrelevant whether homogeneity is purportedly established in terms of 'real' or merely 'phenomenal' objects in that domain.

13 Buridanus (1983, pp. 12-14). Cf.: 'All verbs, even in the present tense, which of their very nature can concern future, past and possible things as well as present ones such as "think", "know", "mean" and the like ampliate their terms to all times, future, past and present. And what accounts for this is that a thing can be thought of without any difference of time, namely, abstracted from any place and time. And so, when a thing is thought of in this way, then a thing which was, or will be, or can be may be thought of as well as a thing which [actually] is. Therefore, if I have the common concept from which we take this name "man", then I can think indifferently of all men, past, present and future. And this is why these verbs can concern past or future things as well as present ones' (Albert of Saxony, 1974, Tr. 2, c. 10, 8a regula). For an earlier example of the same explanation of ampliation, see the selection from the Logica Lamberti in Kretzmann and Stump (1988), pp. 104-63, esp. pp. 116-8.

14 I take this to be pretty much the presentation of the issue one can find in a recent paper by Tim Crane (2012), just as in my not-so recent papers (Klima, 2001, 1987).

15 Thus, despite similarities to the contrary, for want of the requisite theoretical background, Tim Crane's and others' proposed solutions to 'the ontological problem of intentional objects' are rather different from our medieval colleagues' dissolution of the problem or rather their refusal to allow the emergence of a pseudo-problem.

16 SD 4.3.8.4: 'Sic autem appellant illos conceptus quia intelligimus res secundum illos conceptus; non sic tamen, per conceptum, ignis calefacit aquam vel lapis tangit terram'.

17 The recent and not-so recent boom in the contemporary literature on the medieval theories of supposition, ampliation, appellation, and other 'properties of terms', would make it impossible to give even a fair sampling of that literature. Thus, I would only mention here some of my earlier work containing direct confrontations of the relevant medieval and contemporary theories, and a useful survey of the specialist literature containing numerous pointers to more detailed or more specific studies: Klima (1988, 1993, 2008, 2010); Read (2011).

\section{References}

Albert of Saxony, Perutilis Logica, Hildesheim: Georg Olms.

Brentano, F. (1995/1874) Psychology from an Empirical Standpoint, London: Routledge. 


\section{INTERNATIONAL JOURNAL OF PHILOSOPHICAL STUDIES}

Buridanus, J. (1983) Questiones Longe super Librum Perihermeneias, (ed). Ria van der Lecq, Utrecht: Ingenium Publishers.

Cohen, S. M. (1982) 'St', Thomas Aquinas on the Immaterial Reception of Sensible Forms', The Philosophical Review 91: 193-209.

Crane, T. (2006) 'Brentano's Concept of Intentional Inexistence', in M. Textor (ed.) The Austrian Contribution to Philosophy, London: Routledge.

. (2012) 'Existence and Quantification Reconsidered', in T. Tahko (ed.) Aristotelian Metaphysics, Cambridge: Cambridge University Press.

Haldane, J. (1983) 'Aquinas on Sense Perception', The Philosophical Review 92: 233-9.

Hoffman, P. (1990) "St', Thomas Aquinas on the Halfway State of Sensible Being', Philosophical Review 99: 73-92.

Klima, G. (1987) 'Existence', Quantification and the Medieval Theory of Ampliation', Doxa 9: 83-112.

. (1988) ARS ARTIUM: Essays in Philosophical Semantics, Medieval and Modern, Budapest: Institute of Philosophy of the Hungarian Academy of Sciences.

. (1993) “Debeo tibi equum”: A Reconstruction of Buridan's Treatment of the Sophisma', in S. L. Read (ed.) Sophisms in Medieval Logic and Grammar: Acts of the 9th European Symposium for Medieval Logic and Semantics, Dordrecht: Kluwer Academic.

(2001) 'Existence and Reference in Medieval Logic', in A. Hieke and E. Morscher (eds) New Essays in Free Logic, Dordrecht: Kluwer Academic.

-. (2008) 'The Nominalist Semantics of Ockham and Buridan: A Rational Reconstruction', in D. Gabbay and J. Woods (eds) Handbook of the History of Logic, Amsterdam: North Holland. University Press.

-. (2010) 'Natural Logic', Medieval Logic and Formal Semantics', Magyar Filozófiai Szemle 54: 58-75.

Kretzmann, N., and E. Stump (eds) (1988) The Cambridge Translations of Medieval Philosophical Texts, Cambridge: Cambridge University Press.

Pasnau, R. (1997) Theories of Cognition in the Later Middle Ages, Cambridge: Cambridge University Press.

Perler, D. (2002) Theorien der Intentionalitaet im Mittelalter, Frankfurt: Vittorio Klostermann GmbH.

Read, S. (2011) 'Medieval Theories: Properties of Terms', in E. N. Zalta (ed.) The Stanford Encyclopedia of Philosophy (Spring), http://plato.stanford.edu/ archives/spr2011/entries/medieval-terms/.

Tweedale, M. (1992) 'Origins of the Medieval Theory that Sensation is an Immaterial Reception of a Form', Philosophical Topics 20: 215-231. 